\title{
N-benzyl-N-methyldecan-1-amine, a phenylamine derivative isolated from garlic cloves, induces G2/M phase arrest and apoptosis in U937 human leukemia cells
}

\author{
JIN-WOO JEONG ${ }^{1}$, SEJIN PARK $^{2}$, CHEOL PARK $^{3}$, YOUNG-CHAE CHANG ${ }^{4}$, DONG-OH MOON $^{5}$, \\ SUNG OK KIM ${ }^{6,7}$, GI-YOUNG KIM ${ }^{8}$, HEE-JAE CHA ${ }^{9}$, HEUI-SOO KIM ${ }^{10}$, YOUNG-WHAN CHOI ${ }^{2}$, \\ WUN-JAE KIM ${ }^{11}$, YOUNG HYUN YOO ${ }^{12}$ and YUNG HYUN CHOI ${ }^{13,14}$
}

\begin{abstract}
${ }^{1}$ Center for Core Research Facilities, Daegu Gyeongbuk Institute of Science and Technology, Daegu 711-873;
${ }^{2}$ Department of Horticultural Bioscience, College of Natural Resource and Life Sciences, Busan National University, Miryang 627-706; ${ }^{3}$ Department of Molecular Biology, Dongeui University, Busan 614-714; ${ }^{4}$ Research Institute of Biomedical Engineering and Department of Medicine, Catholic University of Daegu School of Medicine, Daegu 705-718; ${ }^{5}$ Department of Biology Education, Daegu University, Gyeongbuk 712-714; ${ }^{6}$ Team for Scientification of Korean Medical Intervention (BK21 Plus) and Department of Herbal Pharmacology, College of Oriental Medicine, Daegu Haany University, Daegu 706-828; ${ }^{7}$ Department of Biology Education, Daegu University, Gyeongbuk 712-714; ${ }^{8}$ Laboratory of Immunobiology, Department of Marine Life Sciences, Jeju National University, Jeju 690-756; ${ }^{9}$ Departments of Parasitology and Genetics,

Kosin University College of Medicine, Seo-gu, Busan 602-702; ${ }^{10}$ Department of Biological Sciences, College of Natural Sciences, Busan National University, Busan 609-735; ${ }^{11}$ Department of Urology, Chungbuk National University College of Medicine, Cheongju 361-804; ${ }^{12}$ Department of Anatomy and Cell Biology, Dong-A University College of Medicine and Mitochondria Hub Regulation Center, Busan 602-714; ${ }^{13}$ Department of Biochemistry, Dongeui University College of Oriental Medicine, Busan 614-052; ${ }^{14}$ Anti-Aging Research Center and Blue-Bio Industry RIC, Dongeui University, Busan 614-714, Republic of Korea
\end{abstract}

Received February 12, 2014; Accepted May 9, 2014

DOI: 10.3892/or.2014.3215

\begin{abstract}
Epidemiological studies indicate that components of garlic (Allium sativum) have anti-proliferative effects against various types of cancer. In the present study, we investigated the effect of newly isolated phenylamine derivative N-benzyl$\mathrm{N}$-methyldecan-1-amine (NBNMA) from garlic cloves on the inhibition of the growth and apoptosis of human leukemia U937 cells and its potential anticancer mechanism. NBNMA exhibited an antiproliferative effect in U937 cells by inducing cell cycle arrest at the G2/M phase and apoptotic cell death. Western blot analyses revealed that NBNMA decreased the
\end{abstract}

Correspondence to: Dr Young Hyun Yoo, Department of Anatomy and Cell Biology, Dong-A University College of Medicine and Mitochondria Hub Regulation Center, Busan 602-714, Republic of Korea

E-mail: yhyoo@dau.ac.kr

Dr Yung Hyun Choi, Department of Biochemistry, Dongeui University College of Oriental Medicine, Busan 614-052, Republic of Korea

E-mail: choiyh@deu.ac.kr

Key words: N-benzyl-N-methyldecan-1-amine, leukemia U937 cells, $\mathrm{G} 2 / \mathrm{M}$ arrest, apoptosis expression of the regulator genes of $\mathrm{G} 2 / \mathrm{M}$ phase progression, cyclin dependent kinase (Cdk) 2 and $\mathrm{Cdc} 2$ and elevated the expression of the Cdk inhibitor $\mathrm{p} 21^{\text {WAFI/CIPI }}$ in a p53-independent manner. In addition, NBNMA activated caspase- 8 and caspase-9, initiator caspases of the extrinsic and intrinsic pathways of apoptosis, respectively, which led to activation of executioner caspase-3 along with degradation of poly(ADPribose) polymerase. NBNMA-induced apoptosis was observed in parallel with an increased ratio of pro-apoptotic Bax and Bad/anti-apoptotic Bcl-2 and Bcl-xL, and inhibition of inhibitor of apoptosis protein (IAP) family members XIAP and cIAP-1. Furthermore, NBNMA-treated cells displayed enhanced release of cytochrome $c$ from the mitochondria into the cytosol concomitant with a loss of mitochondrial membrane potential and downregulation of Bid, suggesting that NBNMA-induced apoptosis occurred via the extrinsic and intrinsic apoptotic pathways with a possible link to Bid protein activity between the two pathways. These results indicate that NBNMA has promising potential to become a novel anticancer agent for the treatment of leukemia. We provide new insight into the mechanisms underlying the anticancer effect of NBNMA.

\section{Introduction}

Recent epidemiological data indicate that consuming plantbased dietary products offers protection from cancer and 
Table I. ${ }^{1} \mathrm{H}(600 \mathrm{MHz})$ and ${ }^{13} \mathrm{C}$ NMR $(150 \mathrm{MHz})$ data of NBNMA.

\begin{tabular}{|c|c|c|c|c|}
\hline \multirow{2}{*}{$\frac{\text { Position }}{1,5}$} & \multicolumn{2}{|c|}{$\delta_{\mathrm{C}}$} & \multirow{2}{*}{$\frac{\delta_{\mathrm{H}}}{7.59, \mathrm{~d} \mathrm{~J}=7.8}$} & \multirow{2}{*}{$\begin{array}{c}\text { HМBC } \\
134.26,132.02,68.95\end{array}$} \\
\hline & $134.26 \times 2$ & $\mathrm{CH}$ & & \\
\hline 2,4 & $130.47 \times 2$ & $\mathrm{CH}$ & $7.53, \mathrm{t}$ & $130.47,128.10$ \\
\hline 3 & 132.02 & $\mathrm{CH}$ & $7.55, \mathrm{t}$ & 134.26 \\
\hline 6 & 128.10 & $\mathrm{C}$ & & \\
\hline 7 & 68.95 & $\mathrm{CH}_{2}$ & $4.57, \mathrm{~s}$ & $134.26,128.10,65.97,50.34$ \\
\hline 9 & 50.34 & $\mathrm{CH}_{3}$ & $3.05, \mathrm{~s}$ & $68.95,65.97$ \\
\hline 10 & 65.97 & $\mathrm{CH}_{2}$ & $3.33, \mathrm{t}$ & $68.95,50.34,27.57,23.82$ \\
\hline 11 & 23.85 & $\mathrm{CH}_{2}$ & $1.90, \mathrm{~m}, 1.34, \mathrm{~m}$ & $65.97,27.57$ \\
\hline 12 & 27.57 & $\mathrm{CH}_{2}$ & $1.38, \mathrm{~m}$ & \\
\hline \multirow[t]{5}{*}{$13-16$} & 30.85 & $\mathrm{CH}_{2}$ & $1.32-1.34$ & \\
\hline & 30.74 & $\mathrm{CH}_{2}$ & $1.32-1.34$ & \\
\hline & 30.67 & $\mathrm{CH}_{2}$ & $1.32-1.34$ & \\
\hline & 30.58 & $\mathrm{CH}_{2}$ & $1.32-1.34$ & \\
\hline & 30.35 & $\mathrm{CH}_{2}$ & $1.41, \mathrm{t}$ & 27.57 \\
\hline 17 & 33.17 & $\mathrm{CH}_{2}$ & $1.32, \mathrm{~m}$ & \\
\hline 18 & 23.82 & $\mathrm{CH}_{2}$ & $1.90, \mathrm{~m}, 1.34, \mathrm{~m}$ & \\
\hline 19 & 14.60 & $\mathrm{CH}_{3}$ & $0.90, \mathrm{t}$ & $33.17,23.82$ \\
\hline
\end{tabular}

reduces cancer risk. Among the dietary products studied, garlic, Allium sativum, and related Allium vegetables are known for their anticancer potential. Garlic is a member of the lily family and has been widely cultivated and consumed as a food in numerous countries for the past 10,000 years and has been widely used as a popular remedy for various disorders for thousands of years. Compounds in garlic have been recently demonstrated to suppress carcinogen-induced tumor growth in vitro and in vivo (1-3). Epidemiological findings also suggest an inverse relationship between garlic consumption and the incidence of various types of cancers (4-6).

Cell cycle dysregulation and resistance to apoptosis are hallmarks of cancer cells; thus, approaches to induce cell cycle arrest and stimulate apoptotic action could be effective targets for antitumor intervention. Therefore, recent studies have offered novel insights into the molecular mechanisms of garlic component-induced cell cycle arrest and apoptosis $(7,8)$. Modem et al (9) reported that fresh garlic clove extract arrests breast cancer cell growth at the G1 phase. Lund et al (10) and Frantz et al (11) reported that a water-soluble extract of garlic arrests breast and colon cancer cells at the G2/M boundary causing apoptosis. In addition, a crude garlic extract was found to cause caspase-dependent apoptosis in colon cancer cells by modulating Bcl-2 family proteins and mitochondrial dysfunction (12). We previously found that the generation of cellular reactive oxygen species (ROS) plays a pivotal role in initiating apoptotic death by garlic clove hexane extracts in human hepatocarcinoma cells (13). These data suggest that garlic components may affect different signaling pathways according to cell type or culture conditions. These effects are selective for cancer cells, as normal cell lines are resistant to cell cycle arrest and apoptosis following treatment with garlic components $(14,15)$. Moreover, a garlic extract was found to reduce the side effects caused by anticancer agents (1).
We isolated the novel phenylamine derivative N-benzylN-methyldecan-1-amine (NBNMA) from garlic cloves during the course of our bioactive natural product screening program of medicinal foods. To date, no studies have reported the anticancer activity of NBNMA; therefore, we conducted the present study to investigate the in vitro anti-leukemic properties of this compound to substantiate its anticancer activity. We used the human leukemia U937 cell line to identify the molecular effects of NBNMA and found that NBNMA induced $\mathrm{G} 2 / \mathrm{M}$ arrest and apoptosis.

\section{Materials and methods}

Plant materials and isolation of the pure compound. Garlic cloves were purchased directly from the Danyang Food Co. (Danyang, Korea) in January, 2009. The freeze-dried garlic cloves $(1 \mathrm{~kg})$ were ground to a fine powder and then successively extracted at room temperature with n-hexane, ethyl acetate (EtOAc) and 70\% ethanol (EtOH) by using 3,000 ml of each solvent three times to obtain a $3.55 \mathrm{~g}$ hexane extract, a $1.12 \mathrm{~g}$ EtOAc extract, and a $51.05 \mathrm{~g}$ EtOH extract. The EtOH extract (13 g) was evaporated en vacuo and chromatographed on a Diaion HP20 Resin $(0.35 \mathrm{~mm}$; Supelco, Bellefonte, PA, USA) column $(30 \times 3 \mathrm{~cm})$ with a step gradient $(0,25,50$ and $90 \%)$ of EtOH in water and methanol $(\mathrm{MeOH})$ to obtain 21 fractions. Fraction GDPIEIDIP-II $(221.3 \mathrm{mg})$ was separated on a Sephadex LH20 (70 $\mu$ m; Pharmacia Biotech AB, Uppsala, Sweden) column $(100 \times 30 \mathrm{~cm})$ with $\mathrm{CHCl}_{3}: \mathrm{MeOH}: \mathrm{dH}_{2} \mathrm{O}$ (65:35:10) to yield the pure compound (61.2 $\mathrm{mg}$ ).

Determination of the NBNMA structure. NBNMA was obtained as a white sticky compound in $\mathrm{MeOH}$. Liquid chromatography mass-spectrometry analyses indicated a molecular ion at $\mathrm{m} / \mathrm{z} 283$ corresponding to $\left[\mathrm{M}+\mathrm{Na}^{+}\right.$; thus, indicating a 
<smiles>CCCCCCCCCCN(C)Cc1ccccc1</smiles>

B

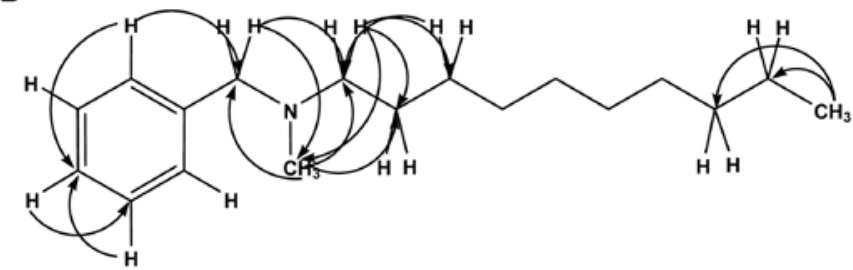

Figure 1. (A) Structure and (B) key heteronuclear multiple-bond correlations of N-benzyl-N-methyldecan-1-amine (NBNMA).

molecular formula of $\mathrm{C}_{18} \mathrm{H}_{30} \mathrm{NNa}$. One- and two-dimensional nuclear magnetic resonance (NMR) analyses with homonuclear and heteronuclear direct and long-range correlations permitted assignments of the ${ }^{1} \mathrm{H}$ and ${ }^{13} \mathrm{C}$ NMR resonances as listed in Table I. The ${ }^{13} \mathrm{C}$ NMR and distortionless enhanced polarization transfer spectra showed 18 signals, including six carbons for one aromatic ring, one phenylic methylene at $\delta_{C} 68.95$, one $\mathrm{N}$-methylene at $\delta_{\mathrm{C}} 65.97$, one $\mathrm{N}$-methyl at $\delta_{C} 50.34$, eight acyclic carbons at $\delta_{C} 23.82-33.17$, and one terminal methyl at $\delta_{\mathrm{C}} 14.40$. The three aromatic protons of the phenyl moiety resonated at $\delta_{H} 7.59,7.53$ and 7.55, respectively, and one phenylic methylene group was located at $\delta_{\mathrm{H}}$ 4.57. One-proton resonance at $\delta_{\mathrm{H}} 3.05$ was due to $\mathrm{N}$-methyl protons. The nine-proton multiplet at $\delta_{\mathrm{H}} 1.32-1.34$ was indicative of an acyclic saturated hydrocarbon group. Heteronuclear multiple-bond correlation spectroscopy (HMBC) correlations observed between $\mathrm{H}-9$ and $\mathrm{C}-7$ and $\mathrm{C}-10$ and from $\mathrm{H}-7$ to C-1, C-5, C-9, and C-10 suggested the presence of an amine group at $\mathrm{N}-8$ attached to the phenyl ring. Cross-peaks were also observed between $\mathrm{H}-10$ and C-7 and C-9 and between $\mathrm{H}-9$ and C-7 and C-10. Correlations between H-19 and C-18 and $\mathrm{C}-17$ established that the terminal methyl of the acyclic methyl group was at C-19. Moreover, the HMBC spectrum confirmed the positions of the $\mathrm{N}$-methyl groups, showing correlations between the $\mathrm{N}-\mathrm{CH}_{3}$ protons at $\delta_{\mathrm{H}} 3.05$ with $\mathrm{N}-8$, and the $\mathrm{N}$-methylene protons showed correlations between resonances at $\delta_{\mathrm{H}} 3.33\left(\mathrm{~N}-\mathrm{CH}_{2}\right)$ and $\mathrm{C}-11$ and $\mathrm{C}-12$. The connectivity of NBNMA was deduced from this information, and the absolute configuration of the compound was established (Fig. 1).

Cell culture. U937 cells were obtained from the American Type Culture Collection (Manassas, VA, USA). The cells were cultured in RPMI-1640 medium containing $10 \%$ fetal bovine serum and $1 \%$ antibiotics (penicillin and streptomycin; Gibco-BRL, Grand Island, NY, USA) under humidified conditions with $5 \% \mathrm{CO}_{2}$ at $37^{\circ} \mathrm{C}$.

Cell viability assay. Cells $\left(1 \times 10^{5}\right.$ cells $\left./ \mathrm{ml}\right)$ were seeded in a 6 -well plate. After a 24-h incubation, the cells were treated with various concentrations of NBNMA for $24 \mathrm{~h}$. Then, $0.5 \mathrm{mg} / \mathrm{ml}$ MTT [3-(4,5-dimethylthiazol-2-yl)-2,5-diphenyltetrazolium bromide; Sigma-Aldrich Chemical Co., St. Louis,
Table II. Gene-specific primers for RT-PCR.

\begin{tabular}{|c|c|}
\hline Gene & Primer sequences \\
\hline $\mathrm{Cdk} 2$ & $\begin{array}{l}\text { S: 5'-GCT TTC TGC CAT TCT CAT CG-3' } \\
\text { A: 5'-GTC CCC AGA GTC CGA AAG AT-3' }\end{array}$ \\
\hline $\mathrm{Cdk} 4$ & $\begin{array}{l}\text { S: 5'-ACG GGT GTA AGT GCC ATC TG-3' } \\
\text { A: 5'-TGG TGT CGG TGC CTA TGG GA-3' }\end{array}$ \\
\hline $\mathrm{p} 21$ & $\begin{array}{l}\text { S: 5'-CTC AGA GGA GGC GCC ATG-3' } \\
\text { A: 5'-GGG CGG ATT AGG GCT TCC-3' }\end{array}$ \\
\hline Cyclin A & $\begin{array}{l}\text { S: 5'-TCC AAG AGG ACC AGG AGA ATA TCA-3' } \\
\text { A: 5'-TCC TCA TGG TAG TCT GGT ACT TCA-3' }\end{array}$ \\
\hline Cyclin B1 & $\begin{array}{l}\text { S: 5'-AAG AGC TTT AAA CTT TGG TCT GGG-3' } \\
\text { A: 5'-CTT TGT AAG TCC TTG ATT TAC CAT G-3 }\end{array}$ \\
\hline Bcl-2 & $\begin{array}{l}\text { S: 5'-CAG CTG CAC CTG ACG-3' } \\
\text { A: 5'-GCT GGG TAG GTG CAT-3' }\end{array}$ \\
\hline Bcl-xL & $\begin{array}{l}\text { S: 5'-CGG GCA TTC AGT GAC CTG AC-3' } \\
\text { A: 5'-TCA GGA ACC AGC GGT TGA AG-3' }\end{array}$ \\
\hline Bax & $\begin{array}{l}\text { S: 5'-ATG GAC GGG TCC GGG GAG-3' } \\
\text { A: 5'- TCA GCC CAT CTT CTT CCA-3' }\end{array}$ \\
\hline Bad & $\begin{array}{l}\text { S: 5'-CAG TGA TCT GCT CCA CAT TC-3' } \\
\text { A: 5'-TCC AGC TAG GAT GAT AGG AC-3' }\end{array}$ \\
\hline XIAP & $\begin{array}{l}\text { S: 5'-GAA GAC CCT TGG GAA CAA CA-3' } \\
\text { A: 5'-CGC CTT AGC TGC TCT CTT CAG T-3' }\end{array}$ \\
\hline cIAP-1 & $\begin{array}{l}\text { S: 5'-TGA GCA TGC AGA CAC ATG C-3' } \\
\text { A: 5'-TGA CGG ATG AAC TCC TGT CC-3' }\end{array}$ \\
\hline cIAP-2 & $\begin{array}{l}\text { S: 5'-CAG AAT TGG CAA GAG CTG G-3' } \\
\text { A: 5'-CAC TTG CAA GCT GCT CAG G-3' }\end{array}$ \\
\hline GAPDH & $\begin{array}{l}\text { S: 5'-CGG AGT CAA CGG ATT TGG TCG TAT-3' } \\
\text { A: 5'-AGC CTT CTC CAT GGT GGT GAA GAC-3' }\end{array}$ \\
\hline
\end{tabular}

$\mathrm{S}$, sense; A, antisense.

MO, USA)] solution was added, and the plates were incubated for an additional $2 \mathrm{~h}$ at $37^{\circ} \mathrm{C}$. The medium was subsequently removed, and dimethyl sulfoxide (Sigma-Aldrich) was added. Optical density was measured at $540 \mathrm{~nm}$ using a microplate spectrophotometer (Dynatech Laboratories, Chantilly, VA, USA).

DAPI staining. A morphological analysis of the treated cells was conducted by fluorescence microscopy using 4,6-diamidino-2-phenylindole dihydrochloride (DAPI) staining to determine whether the growth inhibitory activity of NBNMA is related to the induction of apoptosis. Briefly, the cells were collected and fixed with $3.7 \%$ paraformaldehyde (Sigma-Aldrich) in PBS for $10 \mathrm{~min}$ at room temperature. The fixed cells were washed with PBS and stained with $2.5 \mu \mathrm{g} /$ $\mathrm{ml}$ DAPI solution for $10 \mathrm{~min}$ just prior to observation using a fluorescence microscope (Carl Zeiss, Oberkochen, Germany)

Cell cycle analysis. The cells were exposed to NBNMA for $24 \mathrm{~h}$ to monitor their distribution at various phases of the cell 
cycle. Then, the cells were incubated with $50 \mu \mathrm{g} / \mathrm{ml}$ propidium iodide (Sigma-Aldrich) and 0.1\% Triton X-100 (Sigma-Aldrich) in the dark. After a 30-min incubation, the cells were analyzed by FACScan flow cytometry (Becton-Dickinson, San Jose, CA, USA) equipped with a $488 \mathrm{~nm}$ argon laser (16).

Reverse transcription-polymerase chain reaction (RT-PCR). Total-RNA was extracted using an RNeasy kit (Qiagen, La Jolla, CA, USA), and cDNA was synthesized using an RNA PCR kit (Takara Biomedicals, Osaka, Japan) with the oligo dT primers supplied (Table II), according to the manufacturer's instructions. The resulting amplification products were separated electrophoretically on a $1 \%$ agarose gel and visualized by ethidium bromide (Sigma-Aldrich) staining. In a parallel experiment, amplification of glyceraldehyde-3-phosphate dehydrogenase was used as an internal control to test the integrity of all cDNA and to provide a measure of relative expression.

Western blot analysis. Total cellular protein was isolated from cells washed once in cold PBS and then suspended in $100 \mu \mathrm{l}$ lysis buffer (10 mM Tris-HCl, $\mathrm{pH}$ 8.0, $0.32 \mathrm{M}$ sucrose, $1 \%$ Triton X-100, 5 mM EDTA, 2 mM DTT, 1 mM phenylmethanesulfonyl fluoride). Cytosolic and mitochondrial fractions were prepared using a mitochondrial/cytosol fractionation kit (Alexis Biochemicals, San Diego, CA, USA), according to the manufacturer's instructions. The protein content was determined with the Bio-Rad protein assay reagent (Hercules, CA, USA), using bovine serum albumin as the standard. Protein extracts were reconstituted in sample buffer $[0.062 \mathrm{M}$ Tris-HCl, $2 \%$ sodium dodecyl sulfate (SDS), $10 \%$ glycerol, $5 \% \beta$-mercaptoethanol], and the mixture was boiled for 10 min. Equal amounts of the denatured protein sample were loaded into each lane, separated by SDS-polyacrylamide gel electrophoresis, and transferred to polyvinylidene difluoride membranes (Millipore, Milford, MA, USA). The membranes were incubated with primary antibodies for $2 \mathrm{~h}$, washed twice, and stained with enzyme-linked secondary antibodies (Amersham, Arlington Heights, IL, USA), which were then detected with an enhanced chemiluminescence kit (Millipore) and autoradiography using X-ray film. The primary antibodies were purchased from Santa Cruz Biotechnology Inc. (Santa Cruz, CA, USA), Cell Signaling Technology (Beverly, MA, USA) and Calbiochem (San Diego, CA, USA).

In vitro caspase activity assay. Caspase activity was determined with a colorimetric assay kit that used synthetic tetrapeptides [Asp-Glu-Val-Asp (DEAD) for caspase-3, Ile-Glu-Thr-Asp (IETD) for caspase-8, Leu-Glu-His-Asp (LEHD) for caspase-9] labeled with p-nitroaniline (pNA), following the manufacturer's instructions. Briefly, cells were lysed in the lysis buffer supplied by the manufacturer and according to the protocol. The supernatants were collected and incubated with the supplied reaction buffer containing DTT and DEAD-pNA, IETD-pNA, or LEHD-pNA as the substrate at $37^{\circ} \mathrm{C}$. The reactions were measured by changes in absorbance at $405 \mathrm{~nm}$ using a microplate reader.

Measurement of mitochondrial membrane potential (MMP). MMP values were determined with the dual-emission potential-sensitive probe 5,5',6,6'-tetrachloro-1,1',3,3'-tetraethyl-imidacarbocyanine iodide (JC-1; Sigma-Aldrich), which selectively enters mitochondria, and the color changes reversibly from red to green as the MMP decreases. Briefly, after treatment with NBNMA for $24 \mathrm{~h}$, the cells were stained with $10 \mu \mathrm{M} \mathrm{JC}-1$ for $20 \mathrm{~min}$ at $37^{\circ} \mathrm{C}$ in the dark. Then, the stained cells were washed with ice-cold PBS and analyzed by flow cytometry.

Statistical analysis. All data are presented as mean \pm standard deviation values. Statistical analyses were conducted with Prism ver. 5.0 using one-way ANOVA, followed by Dunnett's or Tukey's test. A P $<0.05$ was considered to indicate a statistically significant result.

\section{Results}

Anti-proliferative effects of NBNMA against U937 cells. The inhibitory growth effects of NBNMA on U937 cells were determined by the MTT assay. As shown in Fig. 2A, $>38 \%$ of cell proliferation was inhibited by $25 \mu \mathrm{g} / \mathrm{ml}$ NBNMA for $24 \mathrm{~h}$, and $50 \mu \mathrm{g} / \mathrm{ml}$ NBNMA resulted in $>63 \%$ inhibition of proliferation after $24 \mathrm{~h}$. Direct observations using an inverted microscope showed that numerous morphological changes occurred in the U937 cells following treatment with NBNMA. In particular, cell shrinkage and cytoplasmic condensation were noted in a dose-dependent manner after NBNMA treatment (Fig. 2C).

Induction of G2/M arrest and apoptosis by NBNMA in U937 cells. U937 cells were treated with different concentrations of NBNMA and were then subjected to flow cytometric analysis following DNA staining to test whether NBNMA affects cell cycle progression. Following a 24-h NBNMA treatment, the percentage of cells in the G2/M phase increased from $21.16 \%$ in the untreated cells to $21.58,30.87$ and $41.66 \%$ in the cells treated with increasing concentrations of NBNMA (Fig. 2B) with a concomitant decrease in the percentage of cells in the $\mathrm{G} 1$ and $\mathrm{S}$ phases. Morphological changes were examined under a fluorescence microscope after a 24-h exposure to elucidate whether NBNMA inhibits U937 cell growth by inducing apoptosis. Following treatment of U937 cells with various NBNMA concentrations for $24 \mathrm{~h}$, chromatin stained with DAPI had a characteristic condensed and fragmented appearance and this effect was concentration-dependent (Fig. 2C). Moreover, treatment of the U937 cells for $24 \mathrm{~h}$ with NBNMA resulted in a concentration-dependent accumulation of cells in the sub-G1 phase (hypodiploid peak) (Fig. 2D). These data confirmed that NBNMA inhibited U937 cell growth via cell cycle arrest and induction of apoptosis.

Effects of NBNMA on the expression of cell cycle-related genes. mRNA and protein expression levels of the key cell cycle regulators between the $\mathrm{G} 2$ and $\mathrm{M}$ phases were examined by RT-PCR and immunoblotting to elucidate the molecular mechanism of NBNMA-induced G2/M arrest in U937 cells. Treatment with NBNMA resulted in reduced transcriptional and translational levels of cyclin-dependent kinase (Cdk)2 and $\mathrm{Cdc} 2$ in a concentration-dependent manner, with no effect on cyclin A or cyclin B1 (Fig. 3). However, the mRNA and protein 
A

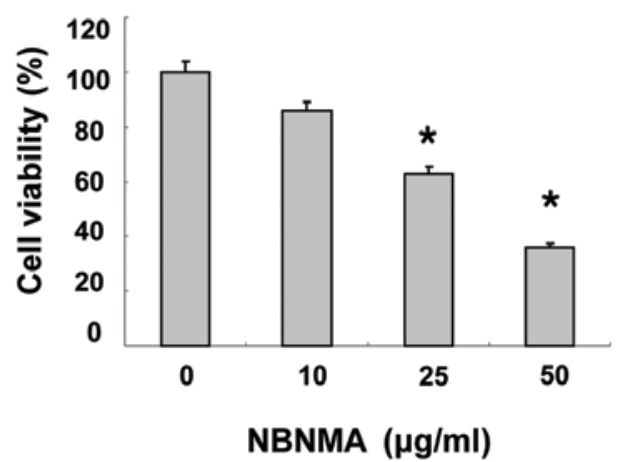

C

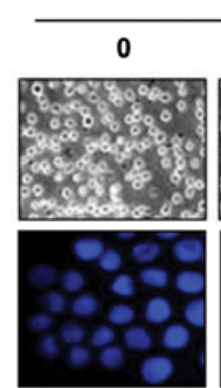

NBNMA $(\mu \mathrm{g} / \mathrm{ml})$

$10 \quad 25$
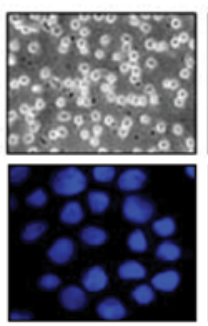

B

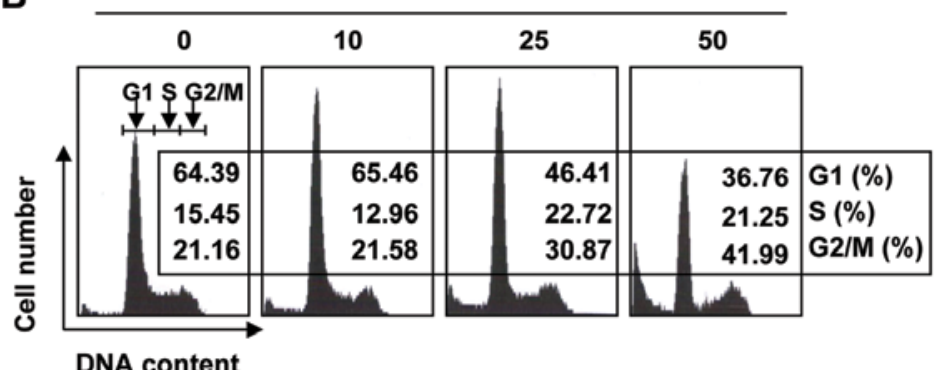

DNA content

D

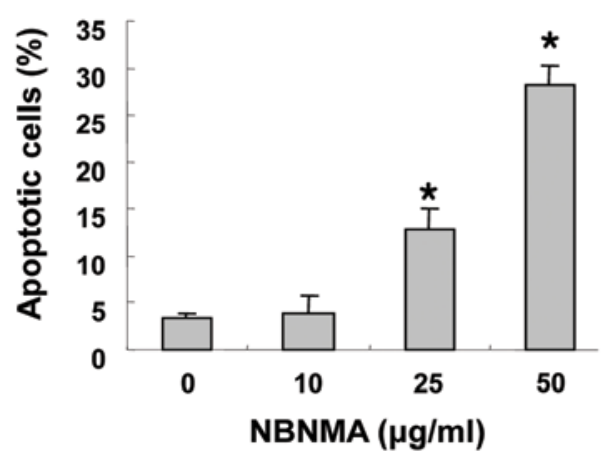

Figure 2. N-benzyl-N-methyldecan-1-amine (NBNMA) causes G2/M arrest and induction of apoptosis in U937 cells. (A) Cytotoxicity was assessed by a metabolic dye-based MTT assay after a 24-h incubation with NBNMA. (B) The cells were stained with propidium iodide and analyzed by flow cytometry. The results are expressed as the percentage of cell distribution at each phase; one image representing each concentration at $24 \mathrm{~h}$ is shown. (C) The morphological changes in the cells were imaged using an inverted microscope (original magnification, x200; upper panels). The cells were fixed and stained with DAPI solution. Stained nuclei were then observed with a fluorescence microscope after a 10-min incubation at room temperature (original magnification, $\mathrm{x} 400$; lower panels). (D) To quantify the degree of apoptosis induced by NBNMA, the percentage of sub-G1 phase cells was determined based on a DNA content histogram. Results are expressed as the percentage of the vehicle control value. Data are the mean \pm standard deviation values from three independent experiments. ${ }^{*} \mathrm{P}<0.05$.

A

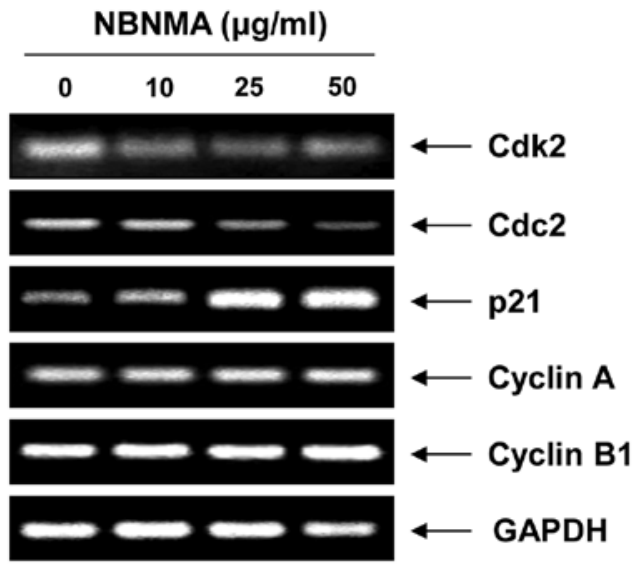

B

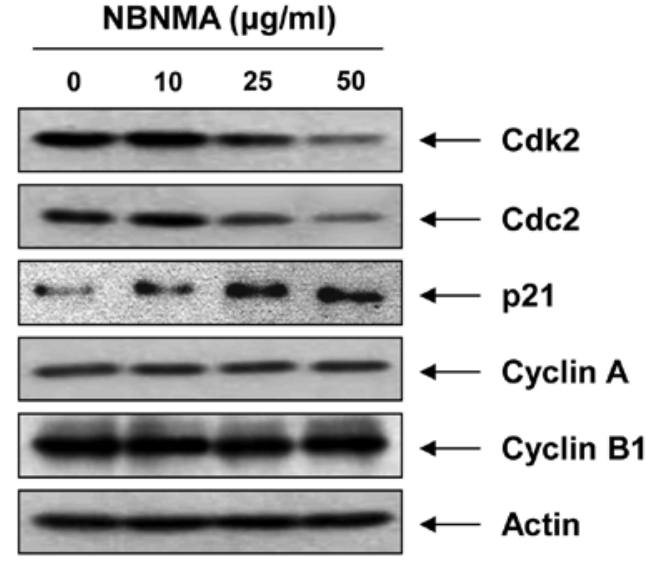

Figure 3. Effects of N-benzyl-N-methyldecan-1-amine (NBNMA) treatment on the expression of cell cycle regulatory genes associated with the G2/M phase in U937 cells. The cells were treated with the indicated concentrations of NBNMA for $24 \mathrm{~h}$, and Cdk2, Cdc2, p21, cyclin A and cyclin B1 levels were assessed by (A) reverse transcription-polymerase chain reaction (RT-PCR) and (B) western blotting, respectively. Results are representative of two or three independent experiments with similar outcomes. GAPDH and actin were used as internal controls for the RT-PCR and western blot assays, respectively.

levels of the Cdk inhibitor p21 WAFI/CIPI increased markedly following treatment with 25 and $50 \mu \mathrm{g} / \mathrm{ml}$ NBNMA for $24 \mathrm{~h}$. Taken together, our data demonstrated that NBNMA inhibits cell cycle progression and contributes to reduced growth by modulating Cdk and p21 levels.
Effects of NBNMA on the expression of Bcl-2 and IAP family members. As NBNMA treatment induced apoptosis in the U937 cells, we examined the effect of NBNMA on the expression of apoptosis regulatory genes including Bcl-2 and inhibitor of apoptosis protein (IAP) family members. The 
A

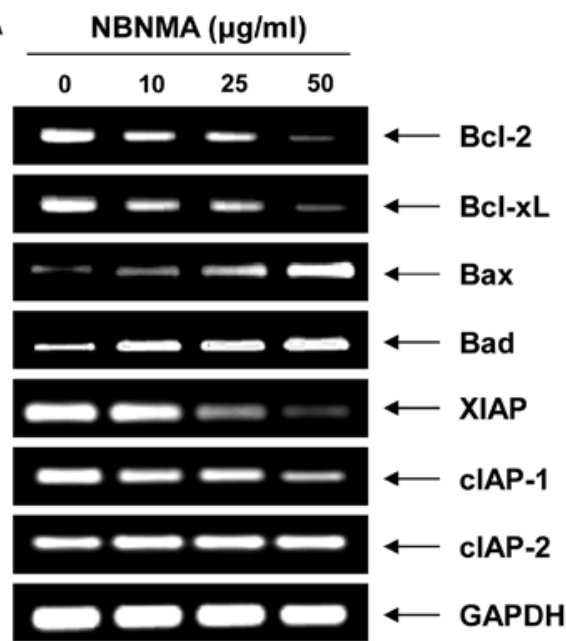

B

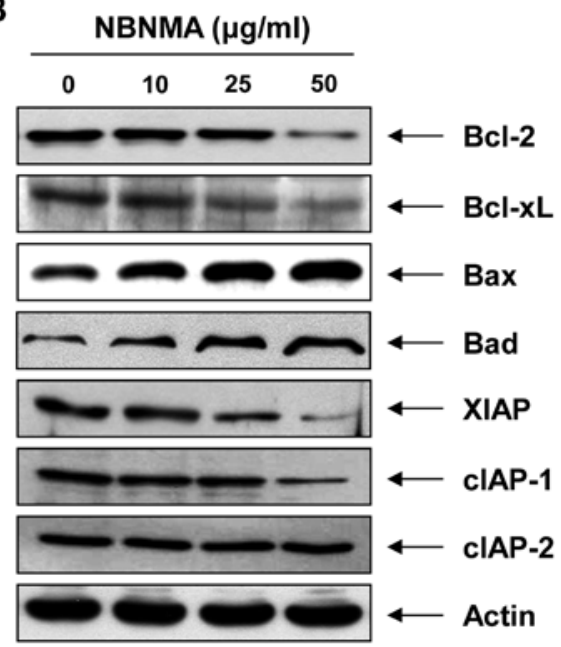

Figure 4. Modification of apoptosis-regulating gene products Bcl-2 and inhibitor of apoptosis protein (IAP) family members by N-benzyl-Nmethyldecan-1-amine (NBNMA) treatment in U937 cells. U937 cells were treated with different concentrations of NBNMA for $24 \mathrm{~h}$. Total-RNA and protein were isolated and analyzed by (A) reverse transcription-polymerase chain reaction (RT-PCR) and (B) immunoblotting assays using the indicated primers and antibodies. GAPDH and actin were used as internal controls for the RT-PCR and western blot assays, respectively.

results of RT-PCR and immunoblotting revealed a marked downregulation of anti-apoptotic Bcl-2 and Bcl-xL in the U937 cells (Fig. 4). However, treatment with NBNMA caused an increase in pro-apoptotic Bax and Bad expression. In addition, relative mRNA and protein expression of anti-apoptotic XIAP and cIAP-1 decreased in a concentration-dependent manner compared to that in the control cells, whereas expression of cIAP-1 was relatively constant in the NBNMA-treated U937 cells.

Activation of caspases and degradation of poly(ADP-ribose) polymerase (PARP). We next examined whether caspases are activated during NBNMA-induced U937 cell death to determine the effectors active in the NBNMA-induced apoptotic pathways. Fig. 5 shows that treatment of U937 cells with NBNMA increased the levels of active caspase- 8 and caspase-9, the initiator caspases of the extrinsic and intrinsic apoptotic pathways, respectively, and their in vitro activities in a concentration-dependent manner. In conjunction with the
A
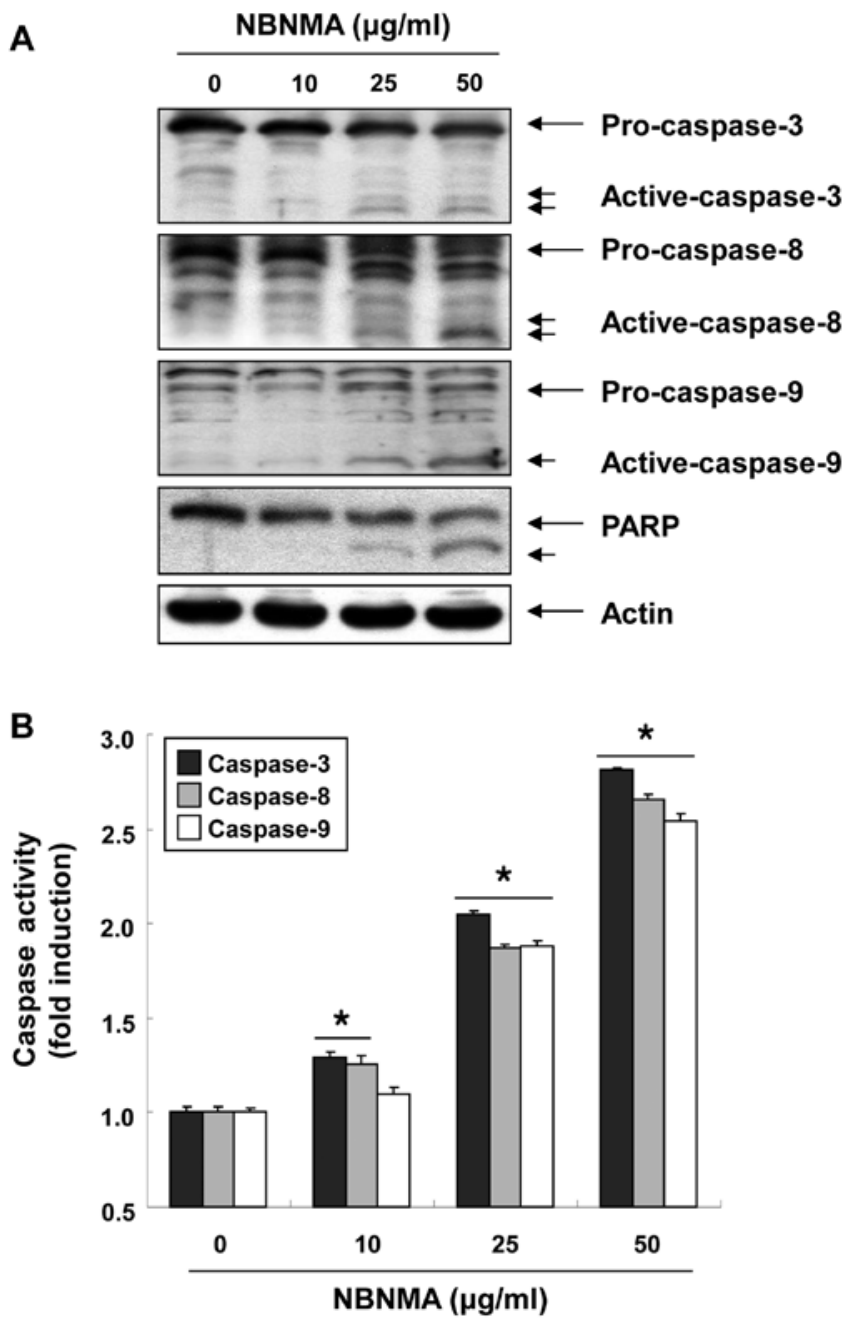

Figure 5. Activation of caspases and degradation of poly(ADP-ribose) polymerase (PARP) by N-benzyl-N-methyldecan-1-amine (NBNMA) treatment in U937 cells. (A) Cells grown under the same conditions as indicated in Fig. 3 were subjected to western blot analysis using the indicated antibodies and an enhanced chemiluminescent detection system. Actin was used as the internal control. (B) Caspase-3, -8 and -9 activity was determined with colorimetric assay kits. Data were normalized to the caspase activity in the control cells and are represented as the fold-change of the control. Data are the means with standard deviations from at least three independent experiments. ${ }^{*} \mathrm{P}<0.05$, significant vs. the control cells.

increase in caspase- 8 and caspase- 9 activity, western blot analysis revealed that NBNMA treatment of U937 cells resulted in proteolytic cleavage of pro-caspase-3 to active caspase-3, a main executioner caspase, with subsequent cleavage of PARP into an $85-\mathrm{kDa}$ fragment.

Effects of NBNMA on apoptosis induction for mitochondrial signaling in U937 cells. Since NBNMA activated caspase-9, we investigated whether it would affect NBNMA-induced apoptosis associated with mitochondrial signaling. We examined the effects of NBNMA on mitochondrial membrane integrity, one of the early events leading to apoptosis, using the JC-1 fluorescent probe. The results in Fig. 6A indicate that treatment with NBNMA clearly elicited dissipation of MMP when compared to that in the control cells. The loss of MMP is usually accompanied by release of cytochrome $c$ into the cytosol, which is involved in activating caspase-3. Therefore, 
A

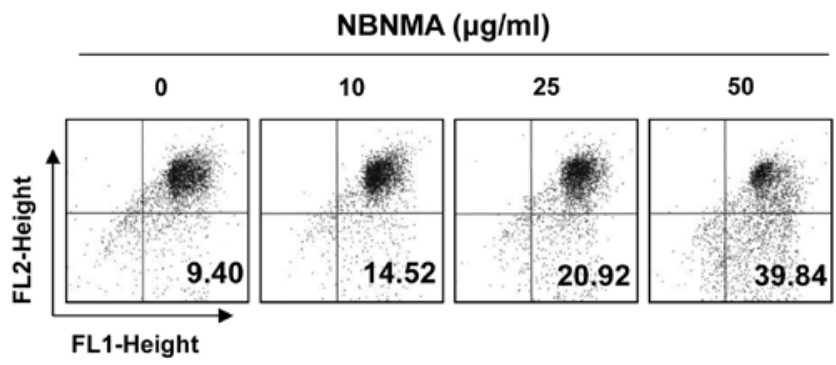

B

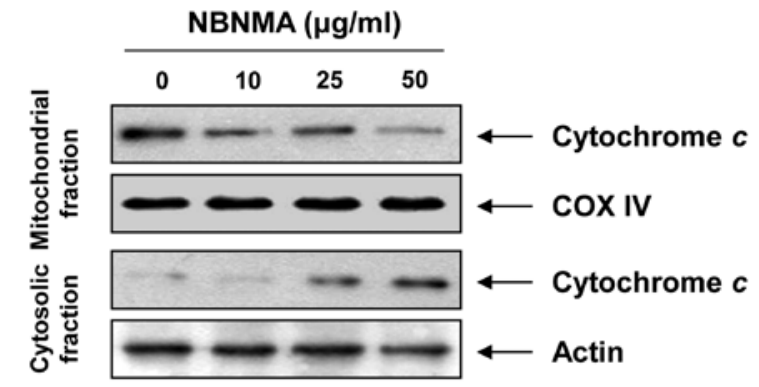

C

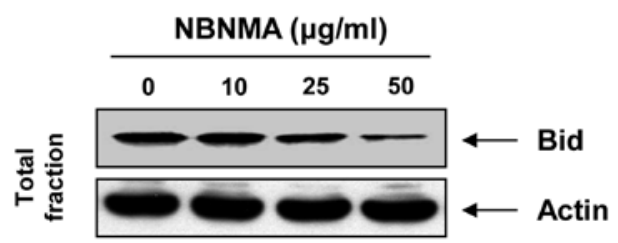

Figure 6. Effects of N-benzyl-N-methyldecan-1-amine (NBNMA) treatment on mitochondrial membrane potential and expression of cytochrome $c$ and Bid in U937 cells. U937 cells were treated with the indicated concentrations of NBNMA for $24 \mathrm{~h}$. (A) The cells were stained with JC-1, and mean JC-1 fluorescence intensity was detected by flow cytometry. Data are expressed as the means of two independent experiments. (B) Mitochondrial and cytosolic proteins were extracted and analyzed by western blotting using the anti-cytochrome $c$ antibody. Actin and cytochrome oxidase IV (COX IV) were used as internal controls for the cytosolic and mitochondrial fractions, respectively. (C) The level of Bid was determined by immunoblotting after treatment of the cells with NBNMA for $24 \mathrm{~h}$. Actin was used as an internal control.

we sought to determine the effects of NBNMA on cytochrome $c$ levels. As shown in Fig. 6B, NBNMA triggered the release of cytochrome $c$ from mitochondria to the cytoplasm, as determined by immunoblotting using mitochondrial and cytosolic extracts. The extrinsic apoptotic signaling cascade starts with activation of caspase- 8 and truncation of Bid (tBid), a $\mathrm{BH} 3$ pro-apoptotic protein, which translocates to the mitochondrial membrane, allowing activation of pro-apoptotic proteins such as caspase-9 and release of cytochrome $c$. As indicated in Fig. 6C, NBNMA treatment caused a decrease in the amount of the Bid pro-form, which is indirect evidence of protein truncation and activation, suggesting that NBNMAinduced apoptosis in U937 cells may occur via activation of caspase- 8 and Bid.

\section{Discussion}

Despite the early detection and precautions to minimize the incidence of leukemia, there is a constant effort to discover alternative strategies to prevent and treat this deadly disease.

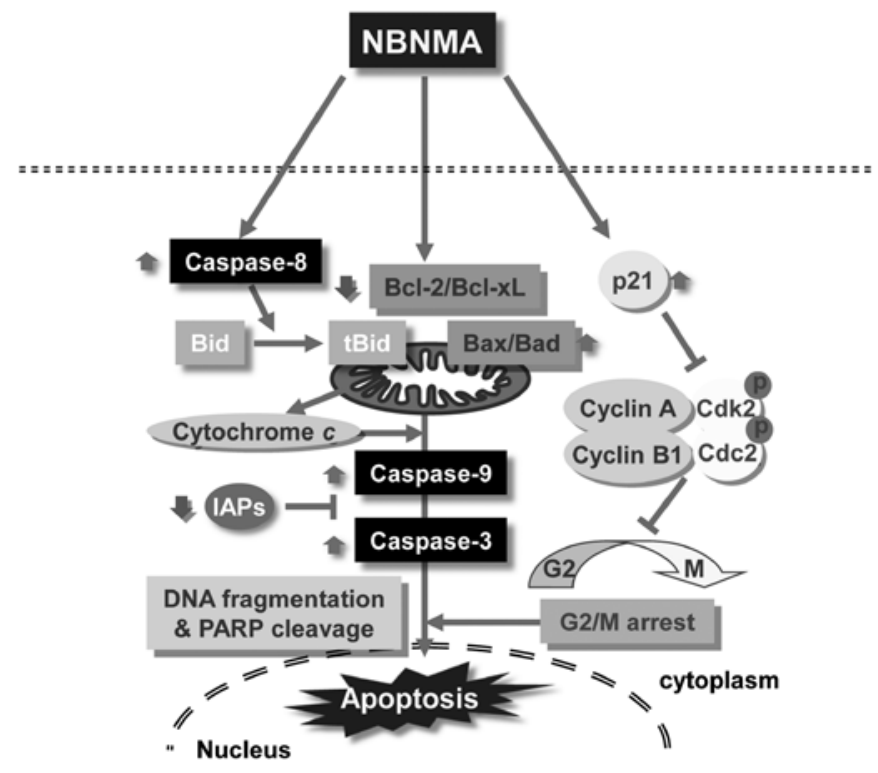

Figure 7. Proposed molecular signaling pathways of NBNMA-induced cell cycle arrest and apoptosis in U937 cells.

To this end, identifying a potent natural molecule that can specifically target leukemic cells with minimal or no toxicity to normal cells would be of great benefit. In the present study, we investigated whether NBNMA, a newly isolated phenylamine derivative from garlic cloves, could inhibit proliferation of leukemia cells using the U937 cell line as an experimental model. We found that NBNMA exerted significant growth inhibitory effects on U937 cells by inducing G2/M phase arrest and apoptotic cell death.

Molecular analyses of human cancers have revealed that cell cycle and apoptosis regulators frequently display encoding gene abnormalities in most common malignancies. Therefore, agents that alter the regulation of cell cycle machinery, resulting in arrest at different phases and thereby reducing the growth and proliferation and even inducing apoptosis of cancer cells may be useful for the development of new anticancer drugs. Cell cycle arrest reflects a requirement to repair cell damage; if not repaired, apoptotic mechanisms are often activated $(17,18)$. Cell cycle progression in mammalian cells is critically regulated by sequential activation of Cdks. The activities and specificities of Cdks are determined by phosphorylation of their corresponding catalytic subunits and by their associations with cyclins, which are differentially expressed during the cell cycle. Cell cycle progression is also regulated by the relative balance between the cellular concentrations of $\mathrm{Cdk}$ inhibitors such as $\mathrm{p} 21$, which may contribute to maintain cell cycle arrest by inactivating the cyclin/Cdk complex $(19,20)$. Of the Cdks, Cdk2 and Cdc2 kinases are activated primarily in association with cyclin A and cyclin B1 during progression of the G2/M phase (21-23). The results of our cell cycle analysis indicated that treatment of U937 cells with NBNMA resulted in significant accumulation of cells in the G2/M phase (Fig. 2B). This cell cycle blockade was associated with a reduction in $\mathrm{Cdk} 2$ and $\mathrm{Cdc} 2$ at both the mRNA and protein levels (Fig. 3). G2/M arrest caused by 
NBNMA was also supported by a significant increase in the expression of $\mathrm{p} 21$, the first mammalian Cdk inhibitor identified, which is an important mediator of cell cycle arrest and apoptosis imposed by the tumor suppressor p53 in response to DNA damage $(24,25)$. Since the p53 gene is deleted in U937 cells (26), it is most likely that the induction of p21 was mediated in a p53-independent manner. This result indicates that NBNMA-induced G2/M arrest in U937 cells might be mediated through p53-independent upregulation of p21, which enhances the formation of heterotrimeric complexes with G2/M cyclins and Cdks, thereby inhibiting their activity.

Apoptosis or programmed cell death is an important homeostatic mechanism for precisely regulating the number of cells and as a defense mechanism to remove unwanted cells. Many studies have shown that an acquired resistance to apoptosis is a hallmark of most types of cancer. Therefore, inducing apoptosis is a protective mechanism against cancer progression, and apoptosis-inducing agents are being investigated as tools to manage cancer. Apoptosis in mammals is controlled by a mitochondrial-mediated intrinsic and a membrane death receptor (DR)-mediated extrinsic pathway $(27,28)$. Caspases are involved in the intrinsic and extrinsic pathways, each possessing specific initiator enzymes, caspase- 9 and caspase- 8 , respectively. The permeability changes and MMP collapse during the intrinsic pathway induce the formation of apoptosomes between the apoptotic protease-activating factor- 1 and caspase- 9 with cytochrome $c$ following its release from mitochondria into the cytosol $(29,30)$. Otherwise, activation of DRs by cross-linking with their respective ligands results in activation of pro-caspase- 8 in the extrinsic pathway. Activated caspase- 8 subsequently promotes proteolytic processing of $\mathrm{Bid}(\mathrm{tBid})$, a pro-apoptotic protein in the $\mathrm{Bcl}-2$ family, that converges into the apoptosis intrinsic pathway downstream from the extrinsic route. Both activated caspase- 8 and caspase- 9 activate downstream executioner caspases such as caspase-3. Activated caspase-3 is responsible for proteolytic degradation of PARP, which occurs at the onset of the apoptosis process $(30,31)$. In the present study, we observed that treatment of U937 cells with NBNMA induced apoptosis associated with activation of caspase- 8 and caspase-9, along with an increase in the active caspase- 3 level and PARP cleavage (Fig. 5). Our experiments also clearly showed that mitochondrial depolarization, release of cytochrome $c$ into the cytosol, and downregulation of Bid were increased after treatment with NBNMA (Fig. 6), suggesting that both the extrinsic and intrinsic pathways are involved in NBNMA-induced U937 cell apoptosis.

Bcl-2 and IAP family members have important regulatory roles in apoptosis. The Bcl-2 family, which has both antiapoptotic (Bcl-2 and Bcl-xL) and pro-apoptotic (Bax and Bad) members, act on mitochondria to either prevent or facilitate the release of apoptogenic factors. Therefore, the Bax:Bad/ $\mathrm{Bcl}-2$ : $\mathrm{Bcl}-\mathrm{xL}$ ratio is a key factor regulating the apoptotic process $(32,33)$. In contrast, the IAP family of proteins are all endogenous inhibitors of apoptosis that bind and inhibit caspases. Thus, they impede the apoptotic process once it has begun. Caspases targeted by IAPs include caspase- 9 and caspase- 3 but not caspase-8 $(34,35)$. We demonstrated that the increase in NBNMA-induced apoptosis was associated with dysregulation of Bcl-2 family members (Fig. 4). Our data also indicate that NBNMA treatment downregulated IAPs and thereby disturbed caspase activation in U937 cells.

In conclusion, the possible effects of NBNMA on cell cycle and apoptosis-related genes and the possible mechanism of action are summarized in Fig. 7. Taken together, we conclude that NBNMA treatment significantly inhibited U937 cell proliferation by causing G2/M phase arrest and inducing apoptosis. Our data provide an important step that might help model the effects of NBNMA for potential future studies with animal models and thereby facilitate the development of nutraceutical products and anticancer drugs using NBNMA.

\section{Acknowledgements}

This study was supported by a National Research Foundation of Korea (NRF) grant funded by the Korean government (MSIP) (nos. 2008-0062611 and 2013-041811).

\section{References}

1. Tsubura A, Lai YC, Kuwata M, Uehara N and Yoshizawa K: Anticancer effects of garlic and garlic-derived compounds for breast cancer control. Anticancer Agents Med Chem 11: 249-253, 2011.

2. Bianchini $\mathrm{F}$ and Vainio $\mathrm{H}$ : Allium vegetables and organosulfur compounds: do they help prevent cancer? Environ Health Perspect 109: 893-902, 2001

3. Milner JA: Mechanisms by which garlic and allyl sulfur compounds suppress carcinogen bioactivation. Garlic and carcinogenesis. Adv Exp Med Biol 492: 69-81, 2001.

4. Kim JY and Kwon O: Garlic intake and cancer risk: an analysis using the Food and Drug Administration's evidence-based review system for the scientific evaluation of health claims. Am J Clin Nutr 89: 257-264, 2009.

5. Fleischauer AT and Arab L: Garlic and cancer: a critical review of the epidemiologic literature. J Nutr 131: S1032-S1040, 2001.

6. Ngo SN, Williams DB, Cobiac L and Head RJ: Does garlic reduce risk of colorectal cancer? A systematic review. J Nutr 137: 2264-2269, 2007.

7. Sperka T, Wang J and Rudolph KL: DNA damage checkpoints in stem cells, ageing and cancer. Nat Rev Mol Cell Biol 13: 579-590, 2012.

8. Canavese M, Santo L and Raje N: Cyclin dependent kinases in cancer: potential for therapeutic intervention. Cancer Biol Ther 13: 451-457, 2012.

9. Modem S, Dicarlo SE and Reddy TR: Fresh garlic extract induces growth arrest and morphological differentiation of MCF7 breast cancer cells. Genes Cancer 3: 177-186, 2012.

10. Lund T, Stokke T, Olsen $\varnothing \mathrm{E}$ and Fodstad $\varnothing$ : Garlic arrests MDA-MB-435 cancer cells in mitosis, phosphorylates the proapoptotic BH3-only protein BimEL and induces apoptosis. Br J Cancer 92: 1773-1781, 2005.

11. Frantz DJ, Hughes BG, Nelson DR, Murray BK and Christensen MJ: Cell cycle arrest and differential gene expression in HT-29 cells exposed to an aqueous garlic extract. Nutr Cancer 38: 255-264, 2000.

12. Su CC, Chen GW, Tan TW, Lin JG and Chung JG: Crude extract of garlic induced caspase-3 gene expression leading to apoptosis in human colon cancer cells. In Vivo 20: 85-90, 2006.

13. Kim HJ, Han MH, Kim GY, Choi YW and Choi YH: Hexane extracts of garlic cloves induce apoptosis through the generation of reactive oxygen species in Hep3B human hepatocarcinoma cells. Oncol Rep 28: 1757-1763, 2012.

14. Na HK, Kim EH, Choi MA, Park JM, Kim DH and Surh YJ: Diallyl trisulfide induces apoptosis in human breast cancer cells through ROS-mediated activation of JNK and AP-1. Biochem Pharmacol 84: 1241-1250, 2012.

15. Xiao D, Herman-Antosiewicz A, Antosiewicz J, Xiao H, Brisson M, Lazo JS and Singh SV: Diallyl trisulfide-induced $\mathrm{G}(2)-\mathrm{M}$ phase cell cycle arrest in human prostate cancer cells is caused by reactive oxygen species-dependent destruction and hyperphosphorylation of Cdc 25C. Oncogene 24: 6256-6268, 2005. 
16. Di X, Andrews DM, Tucker CJ, Yu L, Moore AB, Zheng X, Castro L, Hermon T, Xiao H and Dixon D: A high concentration of genistein down-regulates activin A, Smad3 and other TGF- $\beta$ pathway genes in human uterine leiomyoma cells. Exp Mol Med 44: 281-292, 2012.

17. Medema RH and Macůrek L: Checkpoint control and cancer. Oncogene 31: 2601-2613, 2012.

18. Rozenblat S, Grossman S, Bergman M, Gottlieb H, Cohen Y and Dovrat S: Induction of $\mathrm{G} 2 / \mathrm{M}$ arrest and apoptosis by sesquiterpene lactones in human melanoma cell lines. Biochem Pharmacol 75: 369-382, 2008

19. Lim S and Kaldis P: Cdks, cyclins and CKIs: roles beyond cell cycle regulation. Development 140: 3079-3093, 2013.

20. Sánchez I and Dynlacht BD: New insights into cyclins, CDKs, and cell cycle control. Semin Cell Dev Biol 16: 311-321, 2005.

21. Jeong $\mathrm{AL}$ and Yang Y: PP2A function toward mitotic kinases and substrates during the cell cycle. BMB Rep 46: 289-294, 2013.

22. Lindqvist A, Rodríguez-Bravo V and Medema RH: The decision to enter mitosis: feedback and redundancy in the mitotic entry network. J Cell Biol 185: 193-202, 2009.

23. Porter LA and Donoghue DJ: Cyclin B1 and CDK1: nuclear localization and upstream regulators. Prog Cell Cycle Res 5 335-347, 2003

24. Abbas T and Dutta A: p21 in cancer: intricate networks and multiple activities. Nat Rev Cancer 9: 400-414, 2009.

25. Brown L, Boswell S, Raj L and Lee SW: Transcriptional targets of p53 that regulate cellular proliferation. Crit Rev Eukaryot Gene Expr 17: 73-85, 2007.

26. Danova M, Giordano M, Mazzini G and Riccardi A: Expression of $\mathrm{p} 53$ protein during the cell cycle measured by flow cytometry in human leukemia. Leuk Res 14: 417-422, 1990.
27. Burz C, Berindan-Neagoe I, Balacescu O and Irimie A: Apoptosis in cancer: key molecular signaling pathways and therapy targets. Acta Oncol 48: 811-821, 2009.

28. Fulda $\mathrm{S}$ and Debatin KM: Extrinsic versus intrinsic apoptosis pathways in anticancer chemotherapy. Oncogene 25: 4798-4811, 2006.

29. Liu Y, Bertram CC, Shi Q and Zinkel SS: Proapoptotic Bid mediates the Atr-directed DNA damage response to replicative stress. Cell Death Differ 18: 841-852, 2011.

30. Shamas-Din A, Brahmbhatt H, Leber B and Andrews DW: $\mathrm{BH} 3$-only proteins: Orchestrators of apoptosis. Biochim Biophys Acta 1813: 508-520, 2011

31. TewariM,QuanLT,O'Rourke K,Desnoyers S,ZengZ,BeidlerDR, Poirier GG, Salvesen GS and Dixit VM: Yama/CPP32 beta, a mammalian homolog of CED-3, is a CrmA-inhibitable protease that cleaves the death substrate poly(ADP-ribose) polymerase. Cell 81: 801-809, 1995.

32. Low IC, Kang J and Pervaiz S: Bcl-2: a prime regulator of mitochondrial redox metabolism in cancer cells. Antioxid Redox Signal 15: 2975-2987, 2011.

33. Galluzzi L, Larochette N, Zamzami N and Kroemer G: Mitochondria as therapeutic targets for cancer chemotherapy. Oncogene 25: 4812-4830, 2006.

34. LaCasse EC, Mahoney DJ, Cheung HH, Plenchette S, Baird S and Korneluk RG: IAP-targeted therapies for cancer. Oncogene 27: 6252-6275, 2008.

35. Hunter AM, LaCasse EC and Korneluk RG: The inhibitors of apoptosis (IAPs) as cancer targets. Apoptosis 12: 1543-1568, 2007. 